\title{
Targeted Drug Delivery System: Advantages, Carriers and Strategies
}

\author{
Kousalya Prabahar ${ }^{1}, Z^{2}$ ahraa Alanazi ${ }^{2}$, Mona Qushawy,,4,* \\ ${ }^{1}$ Department of Pharmacy Practice, Faculty of Pharmacy, University of Tabuk, Tabuk, SAUDI ARABIA. \\ ${ }^{2}$ Pharm.D Program, Faculty of Pharmacy, University of Tabuk, Tabuk, SAUDI ARABIA. \\ ${ }^{3}$ Department of Pharmaceutics, Faculty of Pharmacy, University of Tabuk, Tabuk, SAUDI ARABIA. \\ ${ }^{4}$ Department of Pharmaceutics, Faculty of Pharmacy, Sinai University, Alarish, North Sinai, EGYPT.
}

\begin{abstract}
Drug targeting is a new drug delivery system that aims to deliver the drug to the target site of action or site of absorption without releasing the drug at any other non-target site. The delivery system is designed to retain the intact drug without any modification until reaching and releasing at the target site. The targeted drug delivery systems have several advantages over conventional ones as improvement of pharmaceutical activity, low side effects and reduction of the administered dose. The main purpose of the targeted drug delivery system is to obtain the pharmacological action of the therapeutic agent at diseased organs only without affecting the healthy one especially in the case of cancer treatment with chemotherapeutic agents. Drug targeting can be attained using different carriers that maintain and transport the intact drug to preselected organ or tissue. Different types of carriers can be used for drug targeting such as nanotubes and nanowires, nanoshells, quantum dots, nanopores, gold nanoparticles, dendrimers, noisome, ufasomes, virosomes, cubosomes, nanobots and transferosomes. There are different mechanisms of drug targeting such as passive targeting, inverse targeting, active targeting, ligand-mediated targeting, physical targeting, dual targeting and double targeting. The drug targeting is a useful delivery system for delivering the therapeutic agent to a specific site without causing toxicity in other organs.
\end{abstract}

Key words: Drug targeting, Drug delivery system, Pharmacological action, Chemotherapeutic agents, Gold nanoparticles.

\section{INTRODUCTION}

The biological effects of a drug in a patient depend on the pharmacological properties of the drug. ${ }^{1}$ These effects arise due to the interactions between the drug and the receptors at the site of action of the drug. The efficacy of this drug-target interaction has been undermined unless the drug is transported to its site of action at such a concentration and rate that causes the minimum side-effects and maximum therapeutic effects. ${ }^{2}$ Targeted drug delivery, is the method of treatment that involves the transportation of the therapeutic agent to specific tissue without reaching the remaining part of the body. ${ }^{3}$ Therefore, it delivers the medication only to areas of interest within the body. This offers an improved efficacy of treatment and reduces side effects. ${ }^{4}$ It differs from the conventional drug delivery system in that, it gets a release in a dosage form while the former functions by the absorption of the drug through the body's semipermeable membrane. ${ }^{5,6}$

Conventional dosage forms such as injections, oral formulations comprising of solutions and suspensions, tablets, capsules and topical creams and ointments, possess certain disadvantages. ${ }^{7}$ Parenteral delivery of drugs is highly invasive with short time effects. ${ }^{8}$ Oral administration of the drug, although being immensely popular and appropriate but can't be used for certain drugs, such as peptide drugs, due to their poor absorption by the oral route. ${ }^{9}$ These may be degraded in
Submission Date: 17-08-2020; Revision Date: 14-10-2020; Accepted Date: 22-01-2021

DOI: 10.5530/ijper.55.2.72 Correspondence:

Dr. Mona Qushawy ${ }^{3}$ Department of Pharmaceutics, Faculty of Pharmacy, University of Tabuk, Tabuk-71491, SAUDI ARABIA.

${ }^{4}$ Department of

Pharmaceutics, Faculty of Pharmacy, Sinai University, Alarish, North Sinai-45511, EGYPT.

Phone no: +966-0548798401 Email id: mqushawy@ ut.edu.sa

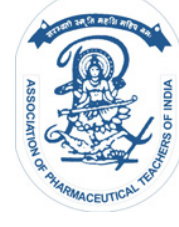

www.ijper.org 
the gastrointestinal tract. Topical ointments and creams have a drawback of being limited to the local effects, rather than the systemic effects. ${ }^{10}$

The technology of the drug delivery system has become advanced and controls the drug bioavailability, drug absorption and pharmacokinetic parameters. ${ }^{11}$ The process of drug targeting requires four principles, first, the ability to load the drug to the target site, second, avoid the degradation by body fluid, third, reaching the target site and fourth, release the drug at the specific site at the predetermined time. ${ }^{12,13}$ Different sites of interest within the body necessitate the use of different drug delivery systems, depending upon the route to be followed.

In drug targeting, the drug may be delivered to ${ }^{4,14}$

- The capillaries of the target site.

- The specific type of cells as in the case of cancer cells.

- Specific tissues or organs which recognize the drug carrier.

\section{Causes of using the targeted drug delivery systems}

There are several causes for the application of a targeted drug delivery system which include: ${ }^{15}$

1. Low drug stability.

2. Poor drug absorption.

3. The short half-life of the drug.

4. The large volume of distribution of the drug.

5. Low drug specificity.

6. Narrow therapeutic index of the drug.

The ideal features of a targeted drug delivery system

The targeted drug delivery system must have certain properties which include: ${ }^{4}$

1. It should be stable, safe (non-toxic), compatible with body fluid and biodegradable.

2. Deliver the drug only to the target site.

3. Control the drug release at a predetermined rate.

4. The rate of drug release not affecting the pharmacological effect.

5. Minimum leakage of the drug during transportation to the target site.

6. Using an inert, biodegradable, or easily eliminated carrier.

7. The preparation process of the drug delivery system should be simple, easy and costless.

\section{The advantages of drug targeting ${ }^{13}$}

1. The protocol of drug administration becomes simpler.
2. The toxicity of the drug is decreased by targeting a specific site.

3. The desired drug response can be reached by a small dose.

4. Avoid the first-pass effect.

5. Improvement in the drug absorption from the target site.

6. Drug targeting resulted in no peak and valley plasma concentration.

\section{The disadvantages of drug targeting ${ }^{16}$}

1. Rapid drug elimination from the body results in high dose frequency.

2. The carrier of the targeted drug delivery system may result in the immune response.

3. The drug delivery system is not localized at the tumor tissue for sufficient time.

4. The diffusion and redistribution of released drugs.

5. The manufacturing, storage and administration of the targeted drug delivery system require high expertise in this field.

6. Toxicity may be raised from drug deposition at the target site.

7. The stability of the product will be difficult to be attained.

\section{Carries applied for drug targeting ${ }^{17}$}

a. Drug targeting can be attained by using carrier systems.

b. The carriers are systems which required for transportation of entrapped drug to target sites.

c. The carriers entrap the drug moiety and deliver it into the target site without releasing it in the nontarget site.

\section{Different types of carriers applied for drug targeting}

There are lots of carriers applied in the targeted drug delivery system as shown by Figure 1, which include:
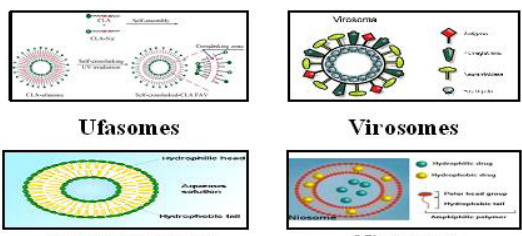

Virosomes
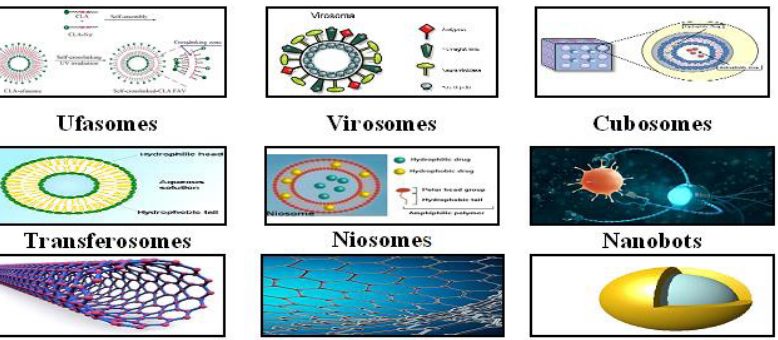

Nanotubes
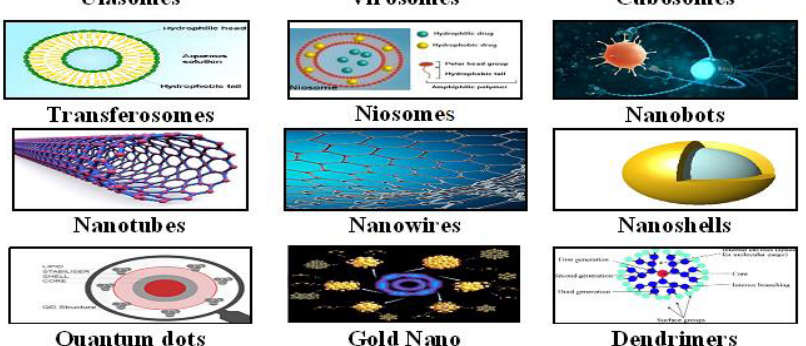

Nanobots

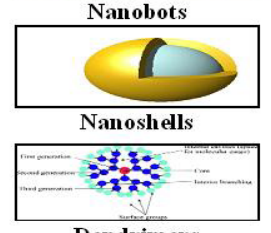

Dendrimers

Figure 1: Different types of carriers for drug targeting. 


\section{Nanotubes}

Nanotubes are a type of drug delivery system which is a hollow cylindrical tube made of carbon that can be easily filled and sealed with the required drug. ${ }^{18,19}$ They are usually used for delivering the drug to the cancer cell. ${ }^{20,21}$ Liu et al. applied carbon nanotube for targeting the tumor in mice. ${ }^{22}$ Also, Mc Devitt et al. achieved tumor targeting with antibody-functionalized, radiolabeled carbon nanotubes. ${ }^{23}$

\section{Nanowires}

It is a wire with a very small diameter made of metal or other organic compounds. It possesses a large surface area, so the surface can be treated to allow the nanowire to bind with specific biological molecules when inserted inside the body. It can be used for detecting the causes and treatment of brain diseases, such as seizures, parkinsonism and similar diseases. ${ }^{24,25}$ This system can treat Parkinson's and similar diseases. ${ }^{26}$ Also, it can be used for the detection and localization of tumors. ${ }^{27}$ Hong et al. used fluorescent zinc oxide nanowires for molecularly targeted imaging of cancer cells. ${ }^{28}$

\section{Nanoshells}

Nanoshells are new strategies of nanoparticles, consisting of a hollow dielectric core of silica covered by a shell of gold ${ }^{29,30}$ It may be used for diagnostic or therapeutic purposes. Nanoshells can be attached with antibodies on their surfaces, allowing them to conjugate certain areas such as cancer cells. ${ }^{31}$ This technique is very effective in targeting the antineoplastic drug. ${ }^{32}$ Loo et al. studied the ability of nanoshells in imaging and treatment of cancer. $^{33}$

\section{Quantum dots}

Quantum dots are nanocrystalline semiconductor particles that possess distinctive optical characters which import them the ability to be used in imaging of tumors. ${ }^{34-36}$ This carrier is effectively used for targeting cancer drugs. ${ }^{37}$ Pardo et al. used quantum dots and nanotubes for cancer targeting and drug delivery. ${ }^{38}$

\section{Nanopores}

They have very tiny holes that allow the passage of DNA molecules in one strand at a time. So, allow highly exact and effective DNA sequencing. ${ }^{39,40}$ This technique has potential in genetic engineering ${ }^{40,41}$ and biotechnology. ${ }^{42}$ Schneider et al. reported DNA translocations through nanopores created in graphene membranes. ${ }^{43}$

\section{Gold nanoparticles}

The gold nanoparticles are used by scientists to develop an ultrasensitive detection system for $\mathrm{DNA}^{44}$ and the protein markers associated with the presence of different types of cancer ${ }^{45}$ like breast and prostate cancer. ${ }^{46}$ Peng et al. used gold nanoparticles in the diagnosis of lung cancer. $^{47}$

\section{Dendrimers}

Dendrimers are synthetic nanoparticles with a specific diameter. ${ }^{48}$ They consist of a control core surrounded by layers of polymers. ${ }^{49}$ There are several sites at the surface of the dendrimers to which the drug may be attached. ${ }^{50}$ They are used in gene transfection and medical imaging. ${ }^{51-55}$ Abd-El-Aziz and Agatemor, reviewed the biomedical applications of dendrimers. ${ }^{56}$

\section{Liposomes}

Liposomes are microscopic bilayer structure vesicles prepared using natural phospholipid. ${ }^{57}$ They can entrap both hydrophilic and lipophilic drugs in the aqueous space or the phospholipid bilayers. ${ }^{58,59}$ The percentage of entrapped drug depend on the physical and chemical properties of the drug and the composition of the lipids. ${ }^{60}$ Huwyler $e t$ al. studied the tumor-targeting using liposomal antineoplastic drugs. ${ }^{61}$

\section{Niosomes}

Niosomes are non-ionic surfactant vesicles which can entrap both hydrophilic and lipophilic drug. The stability of niosomes is higher than liposomes due to the natural properties of phospholipid. ${ }^{62-64}$ It was found that niosomes are effective for targeting antineoplastic drugs, antiinflammatory, anti-bacterial, anti-fungal and antiviral drugs. ${ }^{65}$ Liu et al. designed and evaluated a novel niosomal delivery system of daunorubicin (DNR) for targeting against acute myeloid leukemia (AML). ${ }^{66}$ Ahmed et al. prepared piroxicam niosomes to target the analgesic and anti-inflammatory effect at the pain area. ${ }^{67}$

\section{Ufasomes}

Ufasomes are a dispersion of unsaturated fatty acid vesicles prepared from fatty acid and ionic surfactant (soap) in presence of cholesterol. Ufasomes are a good carrier for drugs intended for topical application. The outermost layer of the skin, which is the stratum corneum, is considered the main barrier for drug penetration. This problem can be overcome by using ufasomes as DDS because the ufasomes consist of lipid membrane which has the ability to attach to the skin. Kaur et al. studied and enhanced the antifungal activity of oxiconazole loaded ufasome against Candida albicans. ${ }^{68}$

\section{Pharmacosomes}

Pharmacosomes are a neutral molecule which carries both positive and negative charges and possesses both 
hydrophilic and lipophilic characters with an optimum ratio of polyphenol with phospholipids in form of a complex. The drug is conjugated to the lipoidal complex by electrostatic force or by forming a hydrogen bond. ${ }^{69}$ The term pharmacosome is derived from the word Pharmakon, meaning drug and soma, meaning carrier. The conjugation of the drug to the lipoidal complex may be in the form of micelles or hexagonal aggregates. ${ }^{4}$ Semalty et al. developed and evaluated pharmacosomes of aceclofenac. ${ }^{70}$

\section{Virosomes}

Virosomes are drug delivery systems described as unilamellar vesicles prepared from phospholipids. ${ }^{71,72}$ The surface of virosomes contains sites to which the virus-derived glycoproteins are attached to facilitate the recognition and targeting of the virosomes to the target site inside the body. ${ }^{73}$ Lucarini et al. design an innovative platform for the treatment of cerebral tumors using erythro-magneto-HA-virosomes. ${ }^{74}$

\section{Cubosomes}

Cubosomes are nanostructured drug delivery systems prepared from certain lipids. They are described as liquid crystalline nanoparticles having a cubic structure suitable for injection. ${ }^{75}$ Azhari et al. used Tween 80 to stabilize phytantriol-based cubosomes for delivering macromolecular therapeutics to the brain. ${ }^{76}$

\section{Nanocrystal}

Nanocrystals are the material having a dimension less than $100 \mathrm{~nm}$ and present in the form of one crystalline structure. ${ }^{77}$ The nanocrystals differ from nanoparticles in that nanoparticles have a dimension of less than 1000 $\mathrm{nm} .{ }^{78}$ Liu et al. studied the importance of drug loading nanocrystals in targeting and treatment of cancer. ${ }^{79}$

\section{Nanobots}

Nanorobotics is a new technology of drug delivery systems. ${ }^{80,81}$ They are a nanoscale machine with a diameter of $10^{-9} \mathrm{~m} .{ }^{80}$ Andhari et al. prepared self-propelling targeted magneto-nanobots for deep tumor penetration. ${ }^{82}$

\section{Transferosomes}

Transferosomes are such a novel vesicular drug delivery system. Transformers are specially self-optimizing, selfregulating, ultra deformable "ultra-flexible". possessing an inner aqueous core surrounded by a complex lipid bilayer with unique properties, due to the presence of "edge activators" into a vesicular membrane, the surfactant has been used as edge activators. So it can penetrate the skin efficiently by squeezing themselves through pores from 5 to 10 times less than their diameter. ${ }^{83,84}$ This will avoid complete rupture of the vesicle and remaining the drug intact after penetrating the skin. ${ }^{85}$ Qushawy et al. prepared miconazole nitrate transferosomal gel for effective treatment of skin candida infection. ${ }^{86}$

\section{Strategies for drug targeting}

There are several strategies for drug targeting as shown by Figure 2 which include:

\section{Passive targeting}

Passive targeting usually refers to the drug delivery systems which target the drug to the systemic circulation. ${ }^{87}$ The passive targeting is done as a response from the body to the physicochemical properties of the drug or the drug delivery system which entrap the drug till reaching the target site, ${ }^{88}$ see Figure 3. Zhang et al. used salinomycin passive targeting micelles for suppression of breast cancer and stem cell cancer. ${ }^{89}$

\section{Active targeting}

In this strategy, the drug targeting is done as a result of the identification of the target group which is attached at the surface of the drug delivery system to the receptors in the target cells. ${ }^{4}$ The target group include bioadhesive nonionic surfactant, antibodies, or albumin protein. ${ }^{90}$ The active targeting has three types, First-order targeting (organ targeting), Second-order targeting (cell targeting) and Third-order targeting (intracellular targeting), ${ }^{91}$ see Figure 3. Zwicke et al. utilized the folate receptor for active targeting of anticancer drugs. ${ }^{92}$

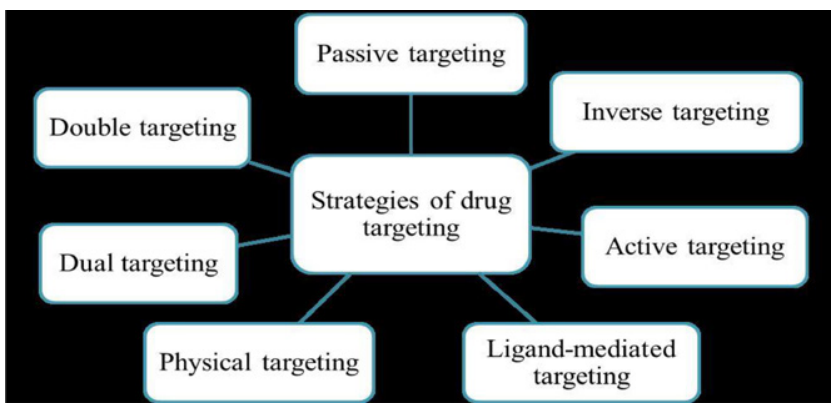

Figure 2: Different strategies for drug targeting.

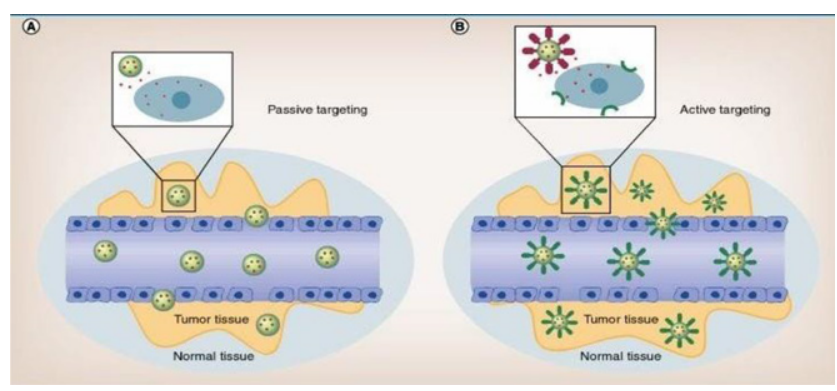

Figure 3: Mechanism of passive targeting and active targeting..$^{93}$ 


\section{Inverse targeting}

The inverse targeting aims to avoid the passive uptake of the drug delivery system by the reticulum-endothelial system (RES). ${ }^{94,95}$ This process can be achieved by suppressing the normal uptake function of RES via injection of a large amount of the blank drug delivery system or large molecules of dextran sulfate to make a saturation of RES and suppress the defense mechanism..$^{90}$ The inverse targeting is very useful for drug targeting to non-RES organs. ${ }^{96}$ Balthasar and Fung, used an inverse targeting strategy for targeting methotrexate to peritoneal tumors. ${ }^{95}$

\section{Ligand mediated targeting}

This type of drug targeting depends on the receptor uptake of natural low-density lipoprotein (LDL) particles and synthetic micro-emulsions of LDL particles covered with Apo proteins. ${ }^{97}$ Veiseh et al. applied a ligand-mediated targeting strategy for the treatment of cancer. ${ }^{98}$

\section{Physical targeting}

The physical targeting strategy aims to achieve external physical change in the drug delivery systems to allow targeting them to the specific site. The physical changes include temperature change, change in $\mathrm{pH}$ and applying an electric field. ${ }^{99}$ This method is very potential for tumor targeting and gene targeting. ${ }^{100,101}$ Weichselbaum et al. applied physical targeting in gene therapy. ${ }^{102}$

\section{Dual targeting}

The dual targeting mechanism involves a drug delivery system in which the carrier has a synergistic effect on the entrapped drug and hence increase the therapeutic effect. ${ }^{4}$ For example, a carrier molecule with antiviral activity when loaded with antiviral drug the therapeutic effect is enhanced. Cui et al. applied dual-targeting for delivery of paclitaxel and curcumin for management of brain tumors. ${ }^{103}$

\section{Double targeting}

The double targeting strategy is a combination of both temporal and spatial, so it is called double targeting. ${ }^{90}$ The spatial delivery involves the targeting of the drug to the target site, while the temporal delivery involves the controlling of drug release at the target site. ${ }^{4}$ Pitto-Barry et al. applied a double targeting mechanism for targeting a dendrimer-loaded anticancer drug to the tumor site. ${ }^{104}$

\section{CONCLUSION}

Drug targeting is a new approach intended for delivering the drug molecules to a specific site or organ inside the body. This delivery system resulted in a reduction in the dose and thus the side effect of the drugs. There are several delivery systems used in drug targeting such as liposome, transferosome, gold nanoparticles, niosomes, cubosome, virosome, nanotube. The targeted drug delivery system is very important in the treatment of several types of cancer such as brain cancer, breast cancer, prostate cancer and colon cancer. Now, there is progress in the field of drug targeting to overcome the problems associated with conventional drug delivery systems.

\section{ACKNOWLEDGEMENT}

The authors would like to acknowledge the Faculty of Pharmacy, University of Tabuk for continuous support.

\section{CONFLICT OF INTEREST}

The authors declare that there is no conflict of interest.

\section{ABBREVIATIONS}

DNA: Deoxyribonucleic acid; DNR: Daunorubicin; AML: Acute myeloid leukemia; RES: Reticulumendothelial system; LDL: Low-density lipoprotein

\section{REFERENCES}

1. Mishra N, Pant P, Porwal A, Jaiswal J, Aquib M. Targeted drug delivery: A review. Am J Pharm Tech Res. 2016;6:2249-3387.

2. Rani K, Paliwal S. A review on targeted drug delivery: Its entire focus on advanced therapeutics and diagnostics. Sch J App Med Sci. 2014;2(1C):328-31.

3. Manish G, Vimukta S. Targeted drug delivery system: A review. Res J Chem Sci. 2011;1(2):135-8

4. Agnihotri J, Saraf S, Khale A. Targeting: New potential carriers for targeted drug delivery system. Int J Pharm Sci Rev Res. 2011;8(2):117-23.

5. Malik R, Garg T, Goyal AK, Rath G. Polymeric nanofibers: Targeted gastroretentive drug delivery systems. J Drug Target. 2015;23(2):109-24.

6. Mishra B, Patel BB, Tiwari S. Colloidal nanocarriers: A review on formulation technology, types and applications toward targeted drug delivery. Nanomedicine Nanotechnol Biol Med. 2010;6(1):9-24.

7. Azarmi S, Roa W, Löbenberg R. Current perspectives in dissolution testing of conventional and novel dosage forms. Int J Pharm. 2007;328(1):12-21.

8. Tice TR, Tabibi SE. Parenteral drug delivery: Injectables. In: Treatise on controlled drug delivery. Routledge. 2017;315-39.

9. Sastry SV, Nyshadham JR, Fix JA. Recent technological advances in oral drug delivery: A review. Pharm Sci Technol Today. 2000;3(4):138-45.

10. Singh MD, Mital N, Kaur G. Topical drug delivery systems: A patent review. Expert Opin Ther Pat. 2016;26(2):213-28.

11. Mills JK, Needham D. Targeted drug delivery. Expert Opin Ther Pat. 1999;9(11):1499-513.

12. Yokoyama M. Drug targeting with nano-sized carrier systems. J Artif Organs. 2005;8(2):77-84.

13. Torchilin VP. Drug targeting. Eur J Pharm Sci. 2000;11:S81-91.

14. Bae YH, Park K. Targeted drug delivery to tumors: Myths, reality and possibility. J Controlled Release. 2011;153(3):198.

15. Mills JK, Needham D. Targeted drug delivery. Expert Opin Ther Pat. 1999;9(11):1499-513.

16. Yokoyama M. Drug targeting with nano-sized carrier systems. J Artif Organs. 2005;8(2):77-84.

17. Ruoslahti E. Drug targeting to specific vascular sites. Drug Discov Today. 2002;7(22):1138-43. 
18. Martincic M, Tobias G. Filled carbon nanotubes in biomedical imaging and drug delivery. Expert Opin Drug Deliv. 2015;12(4):563-81.

19. Popov VN. Carbon nanotubes: Properties and application. Mater Sci Eng R Rep. 2004;43(3):61-102.

20. Madani SY, Naderi N, Dissanayake O, Tan A, Seifalian AM. A new era of cancer treatment: carbon nanotubes as drug delivery tools. Int $\mathrm{J}$ Nanomedicine. 2011;6:2963.

21. Singh BGP, Baburao C, Pispati V, Pathipati H, Muthy N, Prassana SRV, et al. Carbon nanotubes. A novel drug delivery system. Int J Res Pharm Chem. 2012;2(2):523-532.

22. Liu Z, Cai W, He L, Nakayama N, Chen K, Sun X, et al. In vivo biodistribution and highly efficient tumour targeting of carbon nanotubes in mice. Nat Nanotechnol. 2007;2(1):47-52.

23. McDevitt MR, Chattopadhyay D, Kappel BJ, Jaggi JS, Schiffman SR, Antczak $\mathrm{C}$, et al. Tumor targeting with antibody-functionalized, radiolabeled carbon nanotubes. J Nucl Med. 2007;48(7):1180-89.

24. Ellis-Behnke RG, Teather LA, Schneider GE, So K-F. Using nanotechnology to design potential therapies for CNS regeneration. Curr Pharm Des. 2007;13(24):2519-28.

25. Agnihotri J, Saraf S, Khale A. Targeting: New potential carriers for targeted drug delivery system. Int J Pharm Sci Rev Res. 2011;8(2):117-23.

26. Ellis-Behnke R. Nano neurology and the four P's of central nervous system regeneration: preserve, permit, promote, plasticity. Med Clin North Am. 2007;91(5):937-62.

27. Akhter MH, Rizwanullah M, Ahmad J, Ahsan MJ, Mujtaba MA, Amin S. Nanocarriers in advanced drug targeting: setting novel paradigm in cancer therapeutics. Artif Cells Nanomedicine Biotechnol. 2018;46(5):873-84.

28. Hong H, Shi J, Yang Y, Zhang Y, Engle JW, Nickles RJ, et al. Cancertargeted optical imaging with fluorescent zinc oxide nanowires. Nano Lett. 2011;11(9):3744-50.

29. Wu C, Yu C, Chu M. A gold nanoshell with a silica inner shell synthesized using liposome templates for doxorubicin loading and near-infrared photothermal therapy. Int J Nanomedicine. 2011;6:807.

30. Abdollahi SN, Naderi M, Amoabediny G. Synthesis and characterization of hollow gold nanoparticles using silica spheres as templates. Colloids Surf Physicochem Eng Asp. 2013;436:1069-75.

31. Sironmani A, Daniel K. Silver nanoparticles-universal multifunctional nanoparticles for bio sensing, imaging for diagnostics and targeted drug delivery for therapeutic applications. Drug Discov Dev Future. 2011;463-84.

32. Kolhe S, Parikh K. Application of nanotechnology in cancer: A review. Int $\mathrm{J}$ Bioinforma Res Appl. 2012;8(1-2):112-25.

33. Loo C, Lin A, Hirsch L, Lee MH, Barton J, Halas N, et al. Nanoshell-enabled photonics-based imaging and therapy of cancer. Technol Cancer Res Treat. 2004;3(1):33-40.

34. Reddy AK, Rathinaraj BS, Prathyusha P, BHargav TA, Rajani T, Rajamanickam V, et al. Emerging trends of nanotechnology in cancer therapy. Int J Pharamc Biolo Arch. 2011;2(1).

35. Kanaparthy R, Kanaparthy A. The changing face of dentistry: Nanotechnology. Int J Nanomedicine. 2011;6:2799.

36. Nagda D, Rathore KS, Bharkatiya M, Sisodia SS, Nema RK. Bucky balls: A novel drug delivery system. J Chem Pharm RES. 2010;2:240-3.

37. Gao X, Cui Y, Levenson RM, Chung LW, Nie S. In vivo cancer targeting and imaging with semiconductor quantum dots. Nat Biotechnol. 2004;22(8):969-76.

38. Pardo J, Peng Z, Leblanc RM. Cancer targeting and drug delivery using carbon-based quantum dots and nanotubes. Molecules. 2018;23(2):378.

39. Heerema SJ, Dekker C. Graphene nanodevices for DNA sequencing. Nat Nanotechnol. 2016;11(2):127-36.

40. Wanunu M. Nanopores: A journey towards DNA sequencing. Phys Life Rev. 2012;9(2):125-58.

41. Derrington IM, Butler TZ, Collins MD, Manrao E, Pavlenok M, Niederweis M, et al. Nanopore DNA sequencing with MspA. Proc Natl Acad Sci. 2010; 107(37):16060-5.

42. Stoloff DH, Wanunu M. Recent trends in nanopores for biotechnology. Curr Opin Biotechnol. 2013;24(4):699-704.

43. Schneider GF, Kowalczyk SW, Calado VE, Pandraud G, Zandbergen HW, Vandersypen LM, et al. DNA translocation through graphene nanopores. Nano Lett. 2010;10(8):3163-7.
44. Thaxton CS, Georganopoulou DG, Mirkin CA. Gold nanoparticle probes for the detection of nucleic acid targets. Clin Chim Acta. 2006;363(1-2):120-6.

45. Huang X, O'Connor R, Kwizera EA. Gold nanoparticle based platforms for circulating cancer marker detection. Nanotheranostics. 2017;1(1):80.

46. Yezhelyev MV, Gao X, Xing Y, Al-Hajj A, Nie S, O'Regan RM. Emerging use of nanoparticles in diagnosis and treatment of breast cancer. Lancet Oncol. 2006;7(8):657-67.

47. Peng G, Tisch U, Adams O, Hakim M, Shehada N, Broza YY, et al. Diagnosing lung cancer in exhaled breath using gold nanoparticles. Nat Nanotechnol. 2009;4(10):669-73.

48. Myers VS, Weir MG, Carino EV, Yancey DF, Pande S, Crooks RM. Dendrimerencapsulated nanoparticles: New synthetic and characterization methods and catalytic applications. Chem Sci. 2011;2(9):1632-46.

49. Nanjwade BK, Bechra HM, Derkar GK, Manvi FV, Nanjwade VK. Dendrimers: Emerging polymers for drug-delivery systems. Eur J Pharm Sci. 2009;38(3):185-96.

50. Garg T, Singh O, Arora S, Murthy R. Dendrimer: A novel scaffold for drug delivery. Int J Pharm Sci Rev Res. 2011;7(2):211-20.

51. Svenson S, Tomalia DA. Dendrimers in biomedical applications-reflections on the field. Adv Drug Deliv Rev. 2012;64:102-15.

52. Balogh L, Bielinska A, Eichman JD, Valluzzi R, Lee I, Baker JR, et al. Dendrimer nanocompositer in medicine. Chim Oggi. 2002;20(5):35-40.

53. Kesharwani $P$, lyer AK. Recent advances in dendrimer-based nanovectors for tumor-targeted drug and gene delivery. Drug Discov Today. 2015;20(5):536-47.

54. Patel HN, Patel PM. Dendrimer applications: A review. Int J Pharm Bio Sci. 2013;4(2):454-63.

55. Liu M, Fréchet JM. Designing dendrimers for drug delivery. Pharm Sci Technol Today. 1999;2(10):393-401.

56. Abd-El-Aziz AS, Agatemor C. Emerging opportunities in the biomedical applications of dendrimers. J Inorg Organomet Polym Mater. 2018;28(2):369-82.

57. Agnihotri J, Saraf S, Khale A. Targeting: New potential carriers for targeted drug delivery system. Int J Pharm Sci Rev Res. 2011;8(2):117-23.

58. Weiner N, Martin F, Riaz M. Liposomes as a drug delivery system. Drug Dev Ind Pharm. 1989;15(10):1523-54.

59. Anwekar H, Patel S, Singhai AK. Liposome-as drug carriers. Int J Pharm Life Sci. 2011;2(7).

60. Heurtault B, Saulnier P, Pech B, Proust JE, Benoit JP. Physico-chemical stability of colloidal lipid particles. Biomaterials. 2003;24(23):4283-300.

61. Huwyler J, Drewe J, Krähenbühl S. Tumor targeting using liposomal antineoplastic drugs. Int J Nanomedicine. 2008;3(1):21.

62. Abdelkader H, Alani AW, Alany RG. Recent advances in non-ionic surfactant vesicles (niosomes): Self-assembly, fabrication, characterization, drug delivery applications and limitations. Drug Deliv. 2014;21(2):87-100.

63. Mahale NB, Thakkar PD, Mali RG, Walunj DR, Chaudhari SR. Niosomes: Novel sustained release nonionic stable vesicular systems-an overview. Adv Colloid Interface Sci. 2012;183:46-54.

64. Moghassemi S, Hadjizadeh A. Nano-niosomes as nanoscale drug delivery systems: An illustrated review. J Controlled Release. 2014;185:22-36.

65. Pravinagurjar N, Chouksey S. Niosome: A promising pharmaceutical drug delivery. Int J Pharm Drug Anal. 2014;2:425-31.

66. Liu F, Jin H, Wang Y, Chen C, Li M, Mao S, et al. Anti-CD123 antibodymodified niosomes for targeted delivery of daunorubicin against acute myeloid leukemia. Drug Deliv. 2017;24(1):882-90.

67. Ahmed A, Ghourab M, Gad S, Qushawy M. The application of PlackettBurman design and response surface methodology for optimization of formulation variables to produce Piroxicam niosomes. Int J Drug Dev Res. 2013;5(2):121-30.

68. Kaur N, Garg R, Devgan M, Singh A. Optimization and Antifungal Activity Determination of Tea Tree Oil Containing Oxiconazole Loaded Ufasomes Gel Against Candida albicans. Energy Environ Focus. 2016;5(4):287-94.

69. Semalty A, Semalty M, Rawat BS, Singh D, Rawat MSM. Pharmacosomes: The lipid-based new drug delivery system. Expert Opin Drug Deliv. 2009;6(6):599-612.

70. Semalty A, Semalty M, Rawat BS, Singh D, Rawat MSM. Development and evaluation of pharmacosomes of aceclofenac. Indian J Pharm Sci. 2010;72(5):576.

71. Huckriede A, Bungener L, Stegmann T, Daemen T, Medema J, Palache AM, et al. The virosome concept for influenza vaccines. Vaccine. 2005;23:S26-38. 
72. Cusi MG. Applications of influenza virosomes as a delivery system. Hum Vaccin. 2006;2(1):1-7.

73. Agnihotri J, Saraf S, Khale A. Targeting: New potential carriers for targeted drug delivery system. Int J Pharm Sci Rev Res. 2011;8(2):117-23.

74. Lucarini G, Sbaraglia F, Vizzoca A, Cinti C, Ricotti L, Menciassi A. Design of an innovative platform for the treatment of cerebral tumors by means of erythromagneto-HA-virosomes. Biomed Phys Eng Express. 2020;6(4):045005.

75. Garg G, Saraf S, Saraf S. Cubosomes: An overview. Biol Pharm Bull. 2007;30(2):350-3.

76. Azhari H, Strauss M, Hook S, Boyd BJ, Rizwan SB. Stabilising cubosomes with Tween 80 as a step towards targeting lipid nanocarriers to the bloodbrain barrier. Eur J Pharm Biopharm. 2016;104:148-55.

77. Suryanarayana C, Froes FH. The structure and mechanical properties of metallic nanocrystals. Metall Trans A. 1992;23(4):1071-81.

78. Elazzouzi-Hafraoui S, Nishiyama Y, Putaux JL, Heux L, Dubreuil F, Rochas C. The shape and size distribution of crystalline nanoparticles prepared by acid hydrolysis of native cellulose. Biomacromolecules. 2008;9(1):57-65.

79. Liu F, Park JY, Zhang Y, Conwell C, Liu Y, Bathula SR, et al. Targeted cancer therapy with novel high drug-loading nanocrystals. J Pharm Sci. 2010;99(8):3542-551.

80. Mali S. Nanorobots: Changing face of healthcare system. Austin J Biomed Eng. 2014;1(3):3.

81. Thangavel K, Balamurugan A, Elango M, Subiramaniyam P, Senrayan M. A survey on nano-robotics in nano-medicine. Nanotechnology. 2014;8:9.

82. Andhari SS, Wavhale RD, Dhobale KD, Tawade BV, Chate GP, Patil YN, et al. Self-propelling targeted Magneto-nanobots for Deep tumor penetration and pH-Responsive intracellular Drug Delivery. Sci Rep. 2020;10(1):1-16.

83. Cevc G. Transfersomes, liposomes and other lipid suspensions on the skin: Permeation enhancement, vesicle penetration and transdermal drug delivery. Crit Rev Ther Drug Carr Syst. 1996;13(3-4)

84. Kulkarni PR, Yadav JD, Vaidya KA, Gandhi PP. Transferosomes: An emerging tool for transdermal drug delivery. Int J Pharm Sci Res. 2011;2(4):735.

85. Rajan R, Jose S, Mukund VB, Vasudevan DT. Transferosomes: A vesicular transdermal delivery system for enhanced drug permeation. J Adv Pharm Technol Res. 2011;2(3):138.

86. Qushawy M, Nasr A, Abd-Alhaseeb M, Swidan S. Design, optimization and characterization of a transfersomal gel using miconazole nitrate for the treatment of candida skin infections. Pharmaceutics. 2018;10(1):26.

87. Hirsjarvi S, Passirani C, Benoit JP. Passive and active tumour targeting with nanocarriers. Curr Drug Discov Technol. 2011;8(3):188-96.

88. Jawahar N, Meyyanathan SN. Polymeric nanoparticles for drug delivery and targeting: A comprehensive review. Int J Health Allied Sci. 2012;1(4):217.

89. Zhang $\mathrm{Y}$, Zhang H, Wang $\mathrm{X}$, Wang J, Zhang $\mathrm{X}$, Zhang $\mathrm{Q}$. The eradication of breast cancer and cancer stem cells using octreotide modified paclitaxel active targeting micelles and salinomycin passive targeting micelles. Biomaterials. 2012;33(2):679-91.

90. Bhargav E, Madhuri N, Ramesh K, Ravi V. Targeted drug delivery: A review. WJPPS. 2013;3(1):150-9.

91. Minko T, Dharap SS, Pakunlu RI, Wang Y. Molecular targeting of drug delivery systems to cancer. Curr Drug Targets. 2004;5(4):389-406.

92. Zwicke GL, Ali MG, Jeffery CJ. Utilizing the folate receptor for active targeting of cancer nanotherapeutics. Nano Rev. 2012;3(1):18496.

93. Bamrungsap S, Zhao Z, Chen T, Wang L, Li C, Fu T, et al. Nanotechnology in therapeutics: A focus on nanoparticles as a drug delivery system. Nanomed. 2012;7(8):1253-71.

94. Schneider CM, Mihaljev T, Herrmann HJ. Inverse targeting: An effective immunization strategy. EPL Europhys Lett. 2012;98(4):46002.

95. Balthasar JP, Fung HL. Inverse targeting of peritoneal tumors: Selective alteration of the disposition of methotrexate through the use of anti-methotrexate antibodies and antibody fragments. J Pharm Sci. 1996;85(10):1035-43.

96. Lee MJ, Lee MH, Shim CK. Inverse targeting of drugs to reticuloendothelial system-rich organs by lipid microemulsion emulsified with poloxamer 338. Int J Pharm. 1995;113(2):175-87.

97. Vyas SP, Sihorkar V. Endogenous carriers and ligands in non-immunogenic site-specific drug delivery. Adv Drug Deliv Rev. 2000;43(2-3):101-64.

98. Veiseh O, Kievit FM, Gunn JW, Ratner BD, Zhang M. A ligand-mediated nanovector for targeted gene delivery and transfection in cancer cells. Biomaterials. 2009;30(4):649-57.

99. Torchilin VP. Drug targeting. Eur J Pharm Sci. 2000;11:S81-91.

100. Weichselbaum RR, Kufe DW, Hellman S, Rasmussen HS, King CR, Fischer $\mathrm{PH}$, et al. Radiation-induced tumour necrosis factor- $\alpha$ expression: Clinical application of transcriptional and physical targeting of gene therapy. Lancet Oncol. 2002;3(11):665-71.

101. Wagner E. Programmed drug delivery: Nanosystems for tumor targeting. Expert Opin Biol Ther. 2007;7(5):587-93.

102. Weichselbaum RR, Kufe DW, Hellman S, Rasmussen HS, King CR, Fischer $\mathrm{PH}$, et al. Radiation-induced tumour necrosis factor- $\alpha$ expression: Clinical application of transcriptional and physical targeting of gene therapy. Lancet Oncol. 2002;3(11):665-71.

103. Cui $Y$, Zhang $M$, Zeng $F$, Jin $H, X u$ Q, Huang $Y$. Dual-targeting magnetic PLGA nanoparticles for codelivery of paclitaxel and curcumin for brain tumor therapy. ACS Appl Mater Interfaces. 2016;8(47):32159-69.

104. Pitto-Barry A, Barry NP, Zava O, Deschenaux R, Dyson PJ, Therrien B. Double targeting of tumours with pyrenyl-modified dendrimers encapsulated in an arene-ruthenium metallaprism. Chem Eur J. 2011;17(6):1966-71.

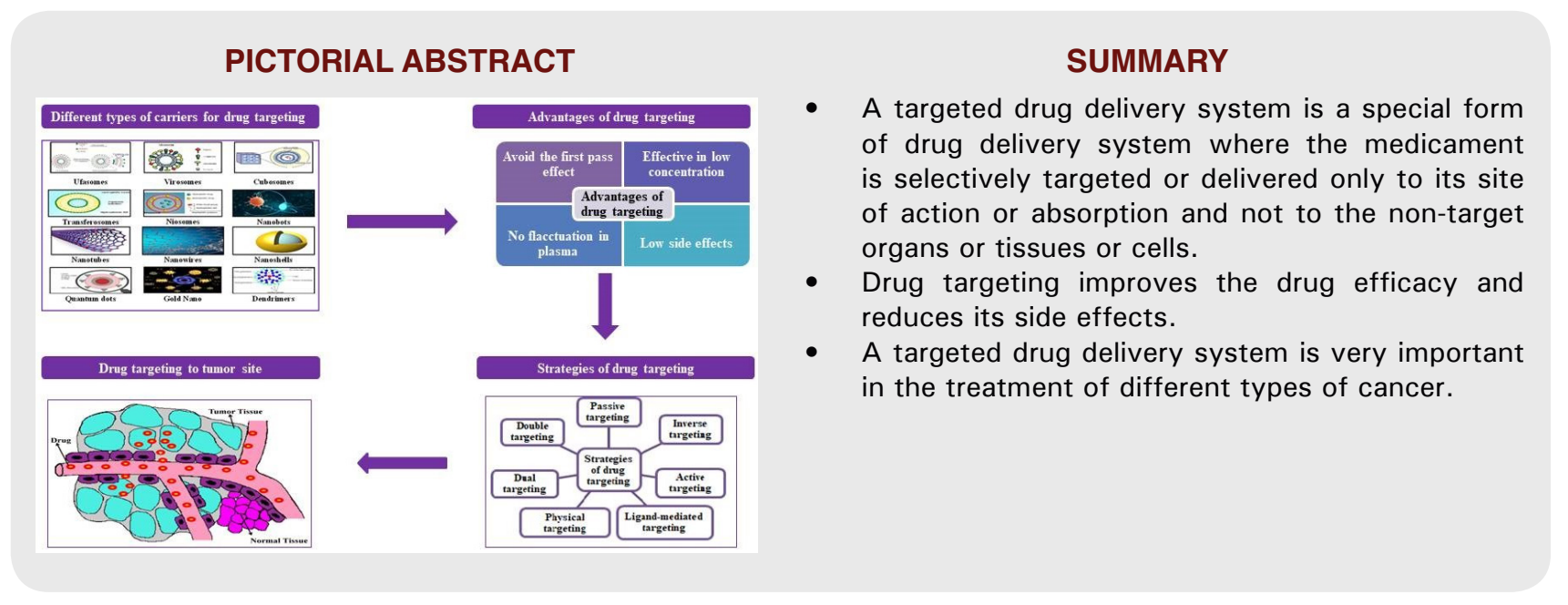




\section{About Authors}

Dr. Kousalya Prabahar is now working as Assistant Professor, in Department of Pharmacy Practice, University of Tabuk. She has published various research papers in peer-reviewed national and international scientific journals. Dr. Kousalya in her 15 years of research-oriented teaching profession acquired funded projects for her research. She is a reviewer of many scientific journals.

Zahraa Alanazi is now a Pharm.D Program student, Faculty of Pharmacy, University of Tabuk, Tabuk, SAUDI ARABIA.

Dr. Mona Qushawy is now working as Assistant Professor, in Department of Pharmaceutics, University of Tabuk. She has published a lot of research articles in the field of pharmaceutical nanotechnology in different reputed journals.

Cite this article: Prabahar K, Alanazi Z, Qushawy M. Targeted Drug Delivery System: Advantages, Carriers and Strategies. Indian J of Pharmaceutical Education and Research. 2021;55(2):346-53. 